\title{
Hidden Realism (II)
}

\author{
Mutsuo M. YaNASE
}

Sophia University, Tokyo

\section{Description of Hidden Realism (continued)}

\section{(4) Aevity as a Hidden Field of Human Existence}

Let us now consider the field of human activities made possible by the existence of Hidden Realism. Descartes divided things into res cogitans and res extensa, and his followers traditionally emphasized that our spiritual activities are completely independent of time and space.

But, when we explore human existence, we are confronted with the fact that, although our spiritual activities transcend time and space, our physical bodies cannot possibly free themselves entirely from the shackles of time and space. In refusing to admit this situation, dualism was supplanted by rationalistic thinking, which is opposed to Anglo-Saxon empiricism. The merging of these opposing philosophies is indeed extremely difficult.

I should like to propose at this point, the medieval philosophical concept of aevity proposed by Boethius s a fundamental meeting ground of philosophical thinking, in somewhat generalized sense.

Once I wrote a short article on this point. There I explained the necessity of introducing this concept from the point of view of philosophy of science, especially concerning the theory of relativity and Quantum mechanics.*

I would like now to consider aevity from the viewpoint of hidden realism as a hidden field of human existence. By this I mean that in our daily life and scientific pursuits, the field of aevity is usually hidden. The field of our everyday life consists of three-dimensional space and one-dimensional time, while the framework which we use in describing natural science is four-dimensional space-time, since it is a combination of the same three-dimensional space and one-dimensional time. In describing our spiritual activities as well as in arranging and describing in sequence our daily experiences, we find that, at times, we are using four-dimensional time and space. But, when we try to touch the existential depths from the standpoint of Hidden Realism, we eventually discover aevity as a hidden field.

We thus realize that the human spirit is not only a physical and sensory existence, but is also aeviternal existence. Metaphorically, the human spirit can

* On Aevrum - between time and eternity -

The Annals of Japan Association for Philosophy of Science Vol. 4, No. 5, March 1975 p. 301 . 
move freely in higher than four-dimensional space-time. And it is at this stage that we realize for the first time that man is not an existence confined to three-dimensional space or four-dimensional space-time. Neither is he an eternal deity. Again, the very fact that man is not a pure spirit or angelic existence totally unrelated to matter, but an intermediate existence, is a proof of his place in aevity. To perceive human existence within aevity is equivalent to accepting the attitude of Hidden Realism.

It is at this point that Hidden Realism, or rather man in his core depths is related to eternity through aevity. It is this all-embracing aevity which comprises higher-dimensional space-time that enables us to reach to the fundamental hidden being - God-. And this is the reason why I consider aevity to be one of the most important elements of Hidden Realism.

\section{(5) Hidden Realism as a Basis of Daily Activity}

As I have already mentioned. Hidden Realism is an attitude which is not only a basis for our academic pursuits, but is also a common sustaining element of human life. Traditionally, this attitude has been often defined as common sense and when raised to the level of a system of philosophy, is known as common sense philosphy.

I consider it here however not as a system of philosophy but as an attitude basic to our daily life. In the case of academic pursuits, we fail to contemplate intentionally our fundamental existence, because our thinking is most often directed outward. In philosophical terms, there is hardly any doubt that our daily life is sustained by naive realism. We quite simply recognize the world around us and, whether it bears any relation to our own existence or not, we consider that the world outside us does exist and is common to everyone. It is this naive realism that is the basis of our attitude in life.

From this point of view, Hidden Realism should be looked on as an attitude which is identical with that of an academic process. In our daily life, our activities are not merely intellectual; they are also emotional and purposeful. As individuals, all of us have our own place in time and space and act as the result of complicated causal relations.

In order to make our actions emotionally balanced, intellectually coordinated and purposeful, not only is it necessary to have a unified external world, but we as individuals must be unified as well. And, as mentioned above, aevity should be the basis of our unified selves, while fundamental recognition of our own existence (reality) will become that of the existence of the outside world (realism).

Probing deeper into fundamental reality, we will find ourselves reaching toward the absolute reality which is the cause of each and every other existence. Normally, we do not extend our thoughts thus far. I would like to repeat that in Hidden 
Realism the presence of the absolute reality is constantly recognized as an ultimate existence. Human beings as individually existing and the existence of an outside world are recognized on the premise that the existence of this absolute reality is recognized, and it is named God in Christian context, as mentioned before.

Conceptually, the existence of God, the outside world and God himself look vague to us. This is because our tools for reaching these realities are not clear-cut concepts. In spite of this fact, however, by choosing elements for our approach which are common to all of us we human beings are able to reach to the ultimate, transcendental existence. In some cases, people can verify the existence of an ultimate existence without relying on logic, but through direct experience.

However, not everyone is able to have such an experience. What we can hope for is that we can reach to God through fuzzy logic. And, as I have already said, Hidden Realism as a sustaining force of four daily life provides the basis for communication, not only for communication in an academic sense, but alos for interchange with other people in our daily life. Hidden Realism exists even when communication is impossible, thus leading us to realize that we possess a common basis for fundamental existence in Hidden Realism. In other words, communion with God who is the transcendental reality and hidden from our eyes is to us all a common basis.

This is the reason why there is only one mankind; this, the ultimate proof that our society consists of groups of individuals whose dignity is inviolable. Without Hidden Realism it would be impossible for us to prove the extent of inviolability of the life of an individual as well as his basic value. Conversely, it is by taking this standpoint that we are able to recognize the dignity of man as an individual; the absolute value of his "einmalig" existence; the "einmalig" existence of history; the common fate and value of the "einmalig" existence of mankind as a whole.

From this standpoint of Hidden Realism we can regard aevity as the dynamic field of force for the action of the human spirit. Thus, even in our daily life, aevity not only enriches it, but also allows us to live more fully and happily. Much more could be said on this extremely important element of our daily life, but I will limit myself here to merely stating the facts as I see them.

\section{Chapter III GONCLUSION}

Now that I have explained what I mean by hidden realism let me try to draw some conclusions and to indicate the lines along which further studies can be conducted.

My starting point, it will be remembered, was the problem of methodology in the individual sciences in the contemporary world; and, moreover, I was interested 
in finding a way to reunite the individual sciences once again. I adopted an existential standpoint, arguing that this project is no mere abstraction but something which touches the deepest area of human existence. Again, it seemed to me that we needed an attitude of mind that would look for a new methodology and search for the unity that runs through all the sciences. I next explained the standpoint of hidden realism and, as a methodological support, I thought of two pillars, namely fuzzy logic and aevity. Here, then, I would like to speak about the practical application of these two principles or pillars, attempting to explain how they relate concretely to the individual sciences which I discussed earlier in my book and about the areas in which progress is possible through this practical application.

\section{Sciences}

First let us consider the conclusions of hidden realism in relation to problems in the area of natural science. As I have already said, in physics, which is probably the most representative area of natural science, after the beginning of the twentieth century, two great theoretical systems arose; namely, the theory of relativity and quantum mechanics. Regarding problems in the theories of individual sciences, we were first of all confronted with the possibility of expanding our notions of time and space and with this the question of whether to think of the theory of relativity itself in a deterministic or non-deterministic way was discussed. Here I believe that the effectiveness of hidden realism lies principally in the practical adoption of the notion of aevity into the theory of relativity. In other words the real problem is as to how aevity can be practically taken into the theory of relativity. This is a point on which there must be considerable discussion and thought, but at present at least one thing can be said: by adopting this notion of aevity we can think of a higher dimension of space-time, a dimension which includes time of one dimension and space of three dimensions.* It seems to me that, having posited this concept, the former dilemma as to whether the theory of relativity should be understood in a deterministic or non-deterministic way will be solved. The reason is that it becomes possible to rethink this dilemma by placing the observer outside Minkowski's four-dimensional space-time. In other words we can think of the subject engaged in measurement not within four-dimensional spacetime but within aevity which transcends these dimensions. Then, even when we think of Minkowski's four-dimensional space-time as an opening up and showing of various pictures in a scroll as determinists say, we freely put conditions from outside on this, so that we can cut off the rigorously deterministic causality. In the way of thinking which existed until now, opinions were divided in regard to the rigorous causality since no real standing was attributed to the outside observer.

* cf. article mentioned on page 129 
Also in quantum mechanics, in the theory of measurement, there arose the problem as to how the observer should be included in the theory. And here again we can rethink this problem by introducing aevity into the theory. That is to say, by once more seeing the whole system, i.e. the object and the observer from outside subject existing in aevity, one can put some order in the theory. In the way of thinking up to now, which considered the observer outside the system tacitly, one was not able to give appropriate value to his position. In regard to this whole problem it will of course be necessary to develop further theory in detail, but I believe that the prospects for the future in this line are very good.

The next important point is the role of fuzzy logic in the problem of measurement in the theory of relativity and quantum mechanics. The importance of the fuzzy concept in these theories is pointed out by the present author.* If one attempts to treat of the problem of the observer by formal logic alone, there arises the danger of the so-called regressus ad infinitum. But one can avoid this by adapting fuzzy logic to the subject of measurement; that is to say, by availing of a logic which is divorced from formal logic. The logic which is applied to the subject of measurement itself must not be formal but fuzzy. In the words of scholastic philosophy, when one makes use of "intentio reflexa", if one does not employ fuzzy logic one cannot describe the real situation of the subject. This is my standpoint. Consequently, here also the two pillars of hidden realism show their full effectiveness. In this whole problem of physics, however, it is important to note that at this point we are not treating of a technical question about the practical application of the concepts of aevity and fuzzy logic to a theory; rather can it be said that the necessary basis for introducing these two instruments is supported by hidden realism. And my opinion is that in this way a possibility for the re-unification of all the sciences is opened up.

Next is the question of mathematics in its relationship to hidden realism. Here the problem consists in establishing fuzzy logic theoretically and also in establishing the theory of fuzzy set, which is its basis. Recently Prof. G. Takeuti \& Dr. S. Titani wrote an article on this problem. They showed that the fuzzy set theory is a special case of Complete Heyting algebra, and suggest that the step function of Zadeh's theory can be generalized such that the whole idee of fuzzy logic will aequire much richer content.**

Thirdly we must consider the suitability of hidden realism for biology. Biology, as is well known, occupies a peculiar position in the natural sciences; and it is difficult to treat it with formal logic, as it would be difficult with the analytic

* Comment on Machida-Namiki-Araki Theory

The Annals of the Japan Association for Philosophy of Science Vol. 6, No. 2, March 1982

** Intuitionistic Fuzzy Logic and Intuitionistic Fuzzy Set Theory, Gaisi Takeuti and Satoko Titani (Preprint) 
methodology used in physics until now. But in the world of biology and in the understanding of the various functions and activities of living things $I$ think it is much more suitable to make use of fuzzy logic rather than of formal logic. In other words, the biological system is essentially an open system and not a closed system like that of physics-and the border line between the biological system and the things outside it was necessarily vague. Consequently one can see how it is quite natural that in this kind of system it should be much more suitable to use a mathematical method in the line of fuzzy logic or fuzzy set rather than formal logic or set theory which has been used until now. In this point again we can have great expectations for future development. It is clear that it will be necessary to use the concept of aevity when one treats of the problem of time in the biological system or of the mutual functioning between biological system and human beings. Until now no one has developed the practical application of hidden realism in the field of the mutual functioning between the biological system and human beings. Much research has yet to be done. Furthermore, as we take in this way of thinking, just as with physics and mathematics there exists the possibility of once more reuniting the scientific systems and doing away with the dichotomy which existed until now between methodology in physics and in biology.

The fourth area is that of the human and cultural and social sciences. There can be no doubt that in this area the methodology of the analytical natural sciences which was employed until now is quite insufficient. And yet one cannot say that an alternative methodology has yet been established. But like in biology, not the formal logic which has been used until now but fuzzy logic will be much more useful here. And I think that clearly there can be hope of methodological progress if we adopt the higher dimension of the world of aevity which transcends fourdimensional space-time. In this area also the methodology of hidden realism is almost unused; but here also as in biology there is great hope that fruitful research can be carried out in the future. I think that fuzzy logic can be of particular value in the methodologies of economics and sociology because it was first of all adopted in the field of system engineering. So it is reasonable to expect that fuzzy logic can be opened up and developed in the area of sociology as well.

\section{Philosophical Problems}

As I have tried to emphasize in these pages, hidden realism is not a system like the individual sciences. Rather should it be considered as something underpinning every system of philosophy. Consequently, if one undertakes to treat of philosophical problems the principal task is to make clear the connection between the individual philosophical systems and the "meta-philosophy" which undergirds them all. Needless to say, between realism as a philosophical system and the 
hidden realism I speak about there is a natural link; but as I wrote before, what I want to say here is that the realism underlying a system of philosophy is not necessarily identical with that system of philosophy. This is the problem we must face in detail when we are confronted with positivistic philosophy or with idealism or existentialism, asking about their connection with hidden realism which is a metaphilosophy. Furthermore, as I said in the last chapter, it is important to ask if there is any connection between atheistic philosophies and the existence of God. For I believe that when people say that their standpoint is that of an atheistic philosophical system they are obliged to posit a theistic meta-philosophy of hidden realism as a premise.

The above is being considered exclusively within the context of western philosophy. And as long as the original source of hidden realism is western philosophy we can treat of the connection between hidden realism and these philosophies in more or less the same qualitative way. The concept of aevity, which is an expansion of space and time, is found originally in western philosophy; and one can think of fuzzy logic as an expansion of formal logic. But besides western philosophy there exists the huge body of non-western philosophy. There is Indian philosophy and the philosophies of Islam, China and Japan. In all these systems, with the exception of India, an outstanding characteristic is the lack of formal logic. Obviously, then, when one analyzes and systematizes these philosophies one must depend not on formal logic but on fuzzy logic. In short, there are a great number of philosophies and it would be necessary to treat of them one by one accurately from the standpoint of hidden realism as a kind of meta-philosophy. The linguistic, cultural and ideological development of these philosophies is very different from that of the philosophy of the West. This means that a good deal of effort will be required to study them. But it is clear that this field contains a rich content which in many respects is superior to western philosophy and certainly cannot be called inferior. Quite certainly concepts like aevity and fuzzy logic are contained in it.

But in all this the problem of God becomes particularly acute. This is because the clear concept of God which is found in western philosophy (irrespective of whether one affirms or denies its objective reality) does not exist in the nonwestern philosophical systems. There are, however, many vague concepts of God-either pantheistic concepts or pan-en-theistic concepts while there are completely atheistic conceptual systems and systems where the explicit notion of God is totally absent. Consequently, the connection between the concept of God in the metaphilosophy which we call hidden realism and the hidden concept of God which we find in each individual philosophy is extremely interesting and gives rise to many problems. These problems have not been adequately studied either in western or non-western philosophies and one can only hope that in the future 
there will be fruitful and rich research in this field.

\section{Literature and Art}

In the realms of literature and aesthetics and the quest for beauty it may well seem that this whole problem looks somewhat heretical. However the question which arises from the standpoint of hidden realism is: how does this hidden realism make its appearance in the writer precisely as he is a man or in his world or in his artistic work which is the expression of his humanity. Needless to say, in the area of aesthetic activity, in addition to literature there are the formative arts and music; and if one attempts to study the practical application of this hidden realism and its appearance in the various human phenomena it is natural that there should arise the necessity of studying not only literature but other fields of art also. I shall first, then, speak about literature and then about other art forms.

It is not necessary or possible here to make a comparative study of western and non-western literature; so I shall confine myself to the role of God and of hidden realism in literature generally.

As in philosophy, so in literature, the problem of God in completely different in western and non-western literature. In western literature the concept of God exists clearly in the minds of the literary authors and the principal question is as to whether the writer in question adopts a positive attitude or some kind of implicit attitude, or whether he accepts or opposes or deliberately ignores the notion of God. But in the non-western world, as was the case with philosophy, the concept of God in literature is vague. If one takes an example from Japan, among the modern writers Catholics are particularly numerous and this in itself gives rise to interesting problems. But there also exist in Japan writers like Kobo Abe who seem to have no concept of God whatever. If one analyzes their work one finds no traces of God, but it would be interesting to see to what extent the God of hidden realism is present. Furthermore from the standpoint of aestheticism in Japan some writers like Junichiro Tanizaki, Yasunari Kawabata, Yukio Mishima and the rest cannot but arouse our interest. And going further back in history to the period prior to the introduction of Buddhism to Japan there is plenty of material for study and reflection about hidden realism in the Manyoshu, the Kokinshu and the Shinkokinshu to say nothing of the Kamakura literature.

Coming again to the West, there can be a fruitful study in asking the question: to what extent can the God of hidden realism be found in the works of writers who positively deny the existence of God? The same question can be asked about the literature of India, Islam, China, Africa and of the vast non-western world. This whole problem can scarcely be studied without cultural and linguistic research from the peoples of these countries. And we can only hope that such a 
study of their literature will be undertaken by the peoples of these countries. But here again the two pillars of hidden realism; namely aevity and fuzzy logic will be very apt and useful instruments for analysis. And in all this one great problem which will necessarily arise is that of the original meaning of beauty. What is the essence of beauty? What is its essence in aesthetic activity and aesthetic works when one considers hidden realism as a metasicence of beauty? Here the question of God as the source of beauty will necessarily arise.

Next there is the fact that hidden realism throws great light upon music which is another area of artistic expression or formative art. For example the problem of timelessness in modern music or the problem of a higher dimension of timethis could be an extremely interesting study if the whole question were considered in the light of aevity. Moreover, time in painting and space in music could be considered from this point of view. Again, the introduction of the notion of aevity into drama or the consideration of drama in the light of aevity could give new inspiration for artistic work and expression in the future. And running through all this once again is the problem of what is beauty. The problem of God is at the basis of hidden realism and the question is as to how it makes its appearance in each individual and in artistic work. Here is an interesting, if undeveloped field.

\section{Theology: the transhumanistic}

I have tried to point out that hidden realism in relationship to other philsophical systems exists at the level of a meta-philosophy. To touch directly the center of man's being is a problem both of the individual's existence and of God who is the basic reality behind contingent existence. It involves not only the history of the individual contingent behing who has been endowed with existence but also the history of the human race. Consequently one must say that hidden realism has a historico-theological problematic. In this sense the level of hidden realism is not at the level of ordinary science or of ordinary philosophy nor can it be said to be theology in the ordinary sense of the word. But at the same time in the way $I$ have tried to expose it, it can be called at heological problem in a broad sense of that word.

When we think of the connection between the indvidual sciences and theology in its more narrow meaning, we are brought up against the problem of theological method. This is a question which has evoked a good deal of discussion in recent times, particularly in Catholic theological circles. It seems to be clear that fuzzy logic rather than formal logic is the most suitable method of procedure in fundamental theology, which can be considered as an individual science in the overall discipline of theology. The same can be said of dogmatic and moral theology where the object of study is man and man's activity and on this point they resemble sociology and biology. This means that from the standpoint of the problems of individual 
theologies, fundamental theology, moral theology and dogmatic theology can be rethought and re-ordered.

Furthermore the concept of aevity has here a very positive measning. Originally this concept was born from controversies in medieval theology; but we can now put aside the controversies and examine its more basic character and meaning, seeing it as the dimension in which exist angels and the human soul in contrast to God who dwells in eternity. In this way much light is thrown on the existence of man which is no longer confined to the one dimension of time but in the manifold dimension of aevity and we can come to some more understanding of the eternity of God, on the one hand, and the relationship between God and man as it constantly appears in the Bible on the other. Obviously we must treat of such problems not only by returning to a certain concept of aevity that was discovered in the middle ages but also by measuring them agianst recent advances in biblical scholarship.

Yet another area of theology which is here of the greatest significance is mysticism. From the very beginning, formal logic has been notoriously unsuitable for judging and evaluating mystical experience. Consequently, mystical phenomena and the theology which endeavours to study them must necessarily make use of fuzzy logic. Moreover, since mystical theology is concerned principally with the human spirit and its purest action, it must necessarily make use of the concept of aevity. Here the mysticisms of Islam and of the whole Orient assume a role of the greatest importance. Here, more than in any other area, hidden realism is of great value; and I personally hold the greatest expectations for the future of this branch of theology. It is comparatively easy for the oriental way of thinking to enter into theology and to affect the individual branches of theology not according to formal logic but according to the fuzzy logic which hidden ralism offers. For the western formal logic upon which medieval theology is built is insufficient and onesided when it approaches the religious phenomena in the East. From now on, the oriental experience of prayer and meditation will undoubtedly exercise a profound influence not only upon mystical theology but also upon liturgy. 